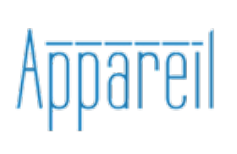

\title{
Appareil
}

$10 \mid 2012$

Lyotard et la surface d'inscription numérique

\section{Présentation du projet de film de Jean-François Lyotard : Le mémorial immémorial (1987)}

Jean-Louis Déotte

\section{(2) OpenEdition}

\section{Journals}

Édition électronique

URL : http://journals.openedition.org/appareil/1505

DOI : 10.4000/appareil. 1505

ISSN : 2101-0714

Éditeur

MSH Paris Nord

\section{Référence électronique}

Jean-Louis Déotte, « Présentation du projet de film de Jean-François Lyotard : Le mémorial immémorial (1987) », Appareil [En ligne], 10 | 2012, mis en ligne le 20 décembre 2012, consulté le 10 décembre 2020. URL : http://journals.openedition.org/appareil/1505; DOI : https://doi.org/10.4000/appareil. 1505

Ce document a été généré automatiquement le 10 décembre 2020.

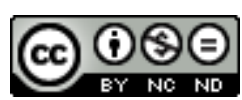

Appareil est mis à disposition selon les termes de la Licence Creative Commons Attribution - Pas d'Utilisation Commerciale - Pas de Modification 4.0 International. 


\title{
Présentation du projet de film de Jean-François Lyotard: Le mémorial immémorial (1987)
}

\author{
Jean-Louis Déotte
}

1 Le sénateur-maire de Caen, J. M. Girault, qui avait participé aux équipes d'urgence, chargées pendant les semaines de la Bataille de Caen (1944) de déblayer les ruines pour sauver les blessés et aider les sinistrés, avait depuis longtemps le projet d'un Mémorial qui leur rendrait hommage. Il connaissait l'existence du Collège international de philosophie, récemment créé, parce que ce dernier avait été associé à la conception de l'exposition Le Pérugin, exercices sur l'espace (1984), exposition didactique et spéculative ayant comme objet principal un tableau du musée des Beaux-Arts de Caen : Le Mariage de la Vierge, du Pérugin.

2 L'idée d'un musée d'histoire du débarquement s'imposa peu à peu à lui et il me chargea d'une exploration sur la « faisabilité » d'une telle institution. Ne connaissant rien à la question, j'explorai la littérature philosophique, ce qui ne me prit pas beaucoup de temps, ainsi que les quelques classiques historiographiques et esthétiques. Je rendis ma copie qui fut publiée par la revue de l'Institut culturel italien de Paris («Suspendre, oublier ", 50 rue de Varenne, n 2 La mémoire exposée, éditions du Centre Culturel italien de Paris, Paris, 1987). Cet article deviendra le programme de ma thèse de philosophie, Le Passage du musée, soutenue en 1990 à l'université de Paris 8, sous la direction de Jean-François Lyotard.

3 L'idée d'associer Jean-François Lyotard au projet de ce qui deviendra finalement un Musée pour la paix, inauguré par le président Mitterand en 1988, germa alors. Bien qu'ayant eu, ou précisément à cause de cela, l'expérience de l'exposition Les Immatériaux au Centre Pompidou en 1985, Lyotard ne s'engagea pas sur cette voie. Et J. M. Girault voulait bien plus qu'un musée d'histoire, plutôt une institution laissant la place à la spéculation philosophique et à l'éthique. C'est la raison pour laquelle il me passa commande d'une fresque de noms ( $30 \mathrm{~m} \times 3)$, laquelle reprenait la problématique de R. Hilberg ( $L a$ destruction des Juifs d'Europe), qui fut réalisée en 1988 et prestement 
détruite lors du dernier réaménagement du Mémorial. Quant à lui, Lyotard transforma la proposition d'intervention philosophique en projet de film : Le mémorial immémorial. Ce devait être un film d'archives qui ne dépassa pas le stade de la demande d'aide à l'écriture du scénario déposée auprès du CNC.

4 Ce projet est intéressant à plus d'un titre : se situant entre les deux textes de Lyotard sur le cinéma : L'acinéma (1973) et Idée d'un film souverain (1995), il peut ouvrir une autre voie, qui reste à problématiser. Sur la présentation cinématographique de l'oubli, sur le statut de l'archive, etc. Mais aussi parce qu'il ne s'agit de rien d'autre que du brouillon de Heidegger et les «juifs» (1988).

\section{AUTEUR}

\section{JEAN-LOUIS DÉOTTE}

Philosophe français, professeur à l'université Paris 8 